\title{
PERCEPÇÃO DOS TRABALHADORES DE ENFERMAGEM SOBRE A DINÂMICA DO TRABALHO E OS PACIENTES EM UM SERVIÇO DE HEMODIÁLISE
}

\author{
Francine Cassol Prestes ${ }^{1}$, Carmem Lúcia Colomé Beck², Juliana Petri Tavares ${ }^{3}$, Rosângela Marion da Silva4, \\ Onélia da Costa Pedro Cordenuzzi $i^{5}$, Geni Burg', Andrea Prochnow ${ }^{7}$
}

\footnotetext{
${ }^{1}$ Mestranda no Programa de Pós-Graduação em Enfermagem da Universidade Federal de Santa Maria (UFSM). Enfermeira da Clínica Renal de Santa Maria-RS. Rio Grande do Sul, Brasil. E-mail: francinecassol@gmail.com

${ }^{2}$ Doutora em Enfermagem. Professor Associado do Departamento de Enfermagem da UFSM. Rio Grande do Sul, Brasil. E-mail: carmembeck@gmail.com

${ }^{3}$ Mestranda no Programa de Pós-Graduação em Enfermagem da UFSM. Professora Substituta do Departamento de Enfermagem da UFSM. Rio Grande do Sul, Brasil. E-mail: jupetritavares@gmail.com

${ }^{4}$ Mestre em Enfermagem. Enfermeira da Unidade de Clínica Cirúrgica do Hospital Universitário de Santa Maria. Rio Grande do Sul, Brasil. E-mail: cucasma@terra.com

${ }^{5}$ Mestranda no Programa de Pós-Graduação em Enfermagem da UFSM. Rio Grande do Sul, Brasil. E-mail: oneliacosta@yahoo. com.br

${ }^{6}$ Mestre em Engenharia de Produção. Enfermeira da Clínica Renal de Santa Maria-RS. Rio Grande do Sul, Brasil. E-mail: geniburg@hotmail.com

7 Acadêmica do Curso de Graduação em Enfermagem da UFSM. Rio Grande do Sul, Brasil. E-mail: andrea.pro@bol.com.br
}

RESUMO: Este estudo objetivou conhecer a dinâmica do trabalho em um serviço de hemodiálise do interior do Rio Grande do Sul, Brasil, e a percepção dos trabalhadores de enfermagem sobre os pacientes em hemodiálise. Trata-se de uma pesquisa qualitativa em que se utilizou a entrevista semi-estruturada. A coleta dos dados ocorreu de março a abril de 2009, com doze trabalhadores de enfermagem. Empregou-se a técnica da análise temática para análise dos dados. O trabalho da enfermagem no serviço de hemodiálise possui uma dinâmica resolutiva, complexa e rotineira. Os trabalhadores afirmaram que os pacientes têm dificuldade de aceitação da doença pela dependência do tratamento, possuem relações sociais e familiares prejudicadas pela doença e buscam essas referências afetivas na equipe de enfermagem. Evidencia-se a complexidade das relações afetivas entre os trabalhadores de enfermagem e os pacientes em hemodiálise, bem como a necessidade de investigações futuras sobre o trabalho em serviços de hemodiálise.

DESCRITORES: Enfermagem. Hemodiálise. Saúde do trabalhador.

\section{NURSING WORKER PERCEPTIONS ON HEMODIALYSIS SERVICE PATIENTS AND LABOR DYNAMICS}

\begin{abstract}
The following study aimed to better understand the labor dynamics of a hemodialysis service in the interior of Rio Grande do Sul, Brazil, as well as nursing worker perceptions on hemodialysis patients. It is a qualitative study in which data was collected through a semi-structured interview applied to twelve nursing workers from March to April of 2009. Thematic analysis was applied to determine that nursing work in hemodialysis service has a resolute, complex, and routine dynamic. These workers affirm that patients have difficulty in accepting the sickness due to the dependency of the treatment, have troubled social and familiar relationships because of the sickness, and search for such references of affection in the nursing team. This study highlights the complexity of affectionate relationships between nursing workers and hemodialysis patients as well as the need for future investigation into hemodialysis services.
\end{abstract}

DESCRIPTORS: Nursing. Renal dialysis. Worker's health.

\section{LA PERCEPCIÓN DE LOS TRABAJADORES DE ENFERMERÍA ACERCA DE LA DINÁMICA DEL TRABAJO Y DE LOS PACIENTES EN UN SERVICIO DE HEMODIÁLISIS}

\begin{abstract}
RESUMEN: Este estudio tuvo el objetivo de conocer la dinámica del trabajo en un servicio de hemodiálisis del interior de Río Grande do Sur, Brasil, y la percepción de los trabajadores de enfermería acerca de los pacientes en hemodiálisis. Se trata de una investigación en la que se utilizó la entrevista semi-estructurada. La recolección de los datos se hizo de marzo a abril de 2009, de la cual participaron doce trabajadores de enfermería. Se utilizó la técnica del análisis temático para el análisis de los datos. El trabajo de enfermería en el servicio de hemodiálisis posee una dinámica resolutiva, compleja y rutinera. Los trabajadores afirmaron que a los pacientes se les hace difícil aceptar la enfermedad a causa de la dependencia del tratamiento, poseen relaciones sociales y familiares perjudicadas por la enfermedad y buscan esas referencias afectivas en el equipo de enfermería. Se evidencia la complejidad de las relaciones afectivas entre los trabajadores de enfermería y los pacientes en hemodiálisis, así como la necesidad de investigaciones futuras sobre el trabajo en servicios de hemodiálisis.

DESCRIPTORES: Enfermería. Diálisis renal. Salud del trabajador.
\end{abstract}




\section{CONSIDERAÇÕES INICIAIS}

Pesquisar a dinâmica do trabalho em um serviço de hemodiálise e a percepção dos trabalhadores de enfermagem sobre os pacientes em hemodiálise foi uma necessidade que emergiu a partir da vivência de enfermeiras que atuam em serviço de hemodiálise e de reflexões sobre a temática no Grupo de Pesquisas Trabalho, Saúde, Educação e Enfermagem, da Universidade Federal de Santa Maria (UFSM). Essa carência se manifestou na medida em que as enfermeiras que gerenciam o serviço planejavam intervenções junto aos trabalhadores de enfermagem, na perspectiva da educação permanente, na direção da melhoria do serviço e da qualidade de vida dos trabalhadores. Além disso, também se observou a escassez de investigações que abordassem essa temática com trabalhadores de enfermagem de serviços de hemodiálise no Brasil.

O trabalho cumpre duas finalidades essenciais na vida do homem, que são a reprodução social e sua expressão como sujeito. A reprodução social implica a possibilidade de satisfazer necessidades, a partir da aquisição de bens de consumo; a expressão como sujeito envolve a procura do prazer e da satisfação com sua obra, realçando as potencialidades como ser humano. ${ }^{1}$

Dessa forma, em nossa sociedade, o trabalho é mediador de integração social, tanto por seu valor econômico quanto cultural, repercutindo, assim, no modo de vida das pessoas e, consequentemente, na sua saúde física e mental. ${ }^{2}$

O trabalho da enfermagem tem como atividade central o cuidado ao ser humano e sua família, o que implica um alto nível de exigência e complexidade; por isso, precisa ser constantemente repensado, no sentido de se oferecer oportunidades com vistas a promover o bem-estar e a felicidade desses trabalhadores. ${ }^{3}$

Dentre as diversas áreas de atuação da enfermagem, destaca-se a especialidade da Nefrologia, um importante campo de atuação dessa profissão, considerando-se tanto as necessidades específicas dos cuidados aos pacientes que possuem diagnóstico médico de Insuficiência Renal Crônica (IRC), quanto a crescente incidência dessa patologia, compreendida como um problema de saúde pública no Brasil. ${ }^{4}$

A IRC caracteriza-se pela perda progressiva e irreversível da função renal, ${ }^{5-6}$ sendo que, com o avanço dos sintomas e agravos relacionados a essa patologia, faz-se necessário o uso da terapia renal substitutiva, ou seja, um tratamento contínuo para substituir a função renal. Dentre as modalidades de terapia renal substitutiva, destaca-se a hemodiálise, que é um procedimento realizado com auxílio de um dialisador que filtra o sangue por meio de circulação extracorpórea.

No ano de 2007, mais de 73 mil indivíduos estavam em terapia renal substitutiva no Brasil, destacando-se que, dentre os que utilizavam método dialítico, 90,8\% estavam em tratamento de hemodiálise. ${ }^{7}$ Esses números poderiam ser ainda mais expressivos, considerando-se que, no Brasil, cerca de $25 \%$ dos pacientes renais vão a óbito antes de iniciar a diálise. ${ }^{4}$

Diante do exposto, apresentamos este estudo, que teve como objetivos conhecer a dinâmica do trabalho da enfermagem em um serviço de hemodiálise e a percepção dos trabalhadores de enfermagem sobre os pacientes em hemodiálise.

\section{PERCURSO METODOLÓGICO}

A pesquisa é do tipo exploratório-descritiva, com abordagem qualitativa. Os sujeitos da pesquisa foram os trabalhadores de enfermagem de um serviço de hemodiálise localizado no interior do Estado do Rio Grande do Sul.

Trata-se de uma empresa privada intrahospitalar, conveniada ao Sistema Único de Saúde (SUS), em que atuam 57 trabalhadores de enfermagem, sendo sete enfermeiras, 36 técnicos de enfermagem e 14 auxiliares de enfermagem, alocados em duas unidades (Matriz e Filial) e que prestam atendimento semanal para aproximadamente 300 pacientes em programa regular de hemodiálise.

A unidade Matriz presta serviço há 24 anos, atendendo 28 pacientes simultaneamente, em três turnos de trabalho. A unidade Filial oferece atendimento há 15 anos, para 26 pacientes simultaneamente, também em três turnos. Os trabalhadores de enfermagem atuam em esquema de escala nos diferentes turnos e unidades.

Os critérios de inclusão dos sujeitos no estudo foram: ser trabalhador de enfermagem, atuar há mais de seis meses no serviço e estar em atividade no período da coleta dos dados. Para a realização do sorteio dos sujeitos de pesquisa, optou-se por considerar a proporcionalidade de entrevistas em relação ao número de trabalhadores de cada categoria profissional, ou seja, enfermeiros, técnicos e auxiliares de enfermagem, bem como dos turnos e unidades de trabalho. Foram entrevistados enfermeiros, técnicos e auxiliares 
de enfermagem de todos os turnos, nas duas unidades, totalizando 12 sujeitos. O número de entrevistas também obedeceu ao critério de saturação das informações, considerando a repetição e homogeneidade das respostas.

Os sujeitos foram convidados a participar da pesquisa, sendo orientados sobre os objetivos do estudo, o caráter voluntário da participação e a garantia do anonimato. Também foram orientados que as informações seriam utilizadas para fins científicos, conforme preceitos da Resolução 196/96 ${ }^{8}$ para pesquisas com seres humanos. Após, foram convidados a ler e assinar o Termo de Consentimento Livre e Esclarecido.

Para a coleta dos dados foi utilizada uma entrevista semiestruturada, com roteiro para orientação e guia de interlocução. $\mathrm{O}$ roteiro se constituiu de maneira a permitir a flexibilidade nas conversas e absorver novos temas e questões trazidas pelo interlocutor. ${ }^{9}$

A entrevista se realizou com auxílio de um gravador digital, mediante a autorização do trabalhador de enfermagem, e teve duração média de 20 minutos. A coleta dos dados ocorreu no período de março a abril de 2009. As entrevistas foram transcritas num editor de textos e lidas para apreensão inicial do conteúdo, sendo que a leitura do material permitiu apreender o conteúdo manifesto e agrupar os fragmentos que se repetiam e/ou possuíam semelhança semântica nos diferentes depoimentos, considerando-se os dois eixos temáticos. Posteriormente, procedeu-se à categorização dos elementos constitutivos de cada tema, completando-se as três etapas de análise: pré-análise, exploração do material, e tratamento dos resultados obtidos e interpretação.

Os dados foram submetidos à análise temática, uma das modalidades da análise de conteúdo, fundamentada na regularidade das afirmações, denotando, dessa forma, estruturas de relevância, valores de referência e comportamentos presentes ou subjacentes nos depoimentos. ${ }^{9}$ Assim, a análise dos dados se realizou em torno de dois eixos temáticos: dinâmica do trabalho da enfermagem no serviço de hemodiálise e percepção dos trabalhadores de enfermagem sobre os pacientes em hemodiálise.

As falas foram identificadas pela letra E para Enfermeiro, as letras TE para Técnico de Enfermagem e AE para Auxiliar de Enfermagem, seguidas de números arábicos, conforme a ordem em que as entrevistas foram realizadas, a fim de preservar a identidade dos sujeitos da pesquisa. O projeto tramitou nos órgãos competentes, sendo aprovado no Comitê de Ética em Pesquisa da Universidade Federal de Santa Maria (UFSM), sob número do Certificado de Apresentação para Apreciação Ética (CAAE) 0274.0.243.000-08 e número do Processo 23081.019038/2008-64, em janeiro de 2009.

\section{RESULTADOS E DISCUSSÃO}

Participaram do estudo duas enfermeiras, seis técnicas de enfermagem e quatro auxiliares de enfermagem, totalizando 12 sujeitos, todos do sexo feminino, que atuavam em todos os turnos. A idade dos trabalhadores variou entre 28 e 60 anos e o tempo de trabalho no serviço de hemodiálise de dois a 16 anos.

A descrição supracitada aponta para uma população de trabalhadores do sexo feminino, em todas as categorias profissionais da enfermagem, e com relativa experiência de vida e também de trabalho no serviço de hemodiálise. Essas características remetem a um período de vivência desses trabalhadores, o que pode representar uma possível adaptação à dinâmica do trabalho no serviço de hemodiálise, bem como permitir o conhecimento das necessidades e dificuldades enfrentadas pelos pacientes em hemodiálise.

A seguir, serão apresentados os eixos temáticos que emergiram do estudo, bem como as suas respectivas categorias.

\section{A dinâmica do trabalho da enfermagem no serviço de hemodiálise}

Neste eixo temático os fragmentos com semelhança semântica foram agrupados em três categorias: materialização da resolutividade do trabalho, complexidade do trabalho mediada pela técnica e interação, e trabalho rotineiro marcado pela pressão do tempo e repetição.

A categoria materialização da resolutividade do trabalho foi relacionada pelos trabalhadores de enfermagem a duas situações: a constatação de que seu trabalho possui caráter fundamental para a manutenção da vida dos pacientes e a possibilidade de perceber, ao final do turno de trabalho, a melhora clínica dos pacientes. A materialização do resultado do trabalho foi apontada pelos profissionais como um diferencial em seu cotidiano laboral.

Alguns deles afirmaram ter consciência de que, sem o seu trabalho, muitos pacientes não estariam vivos, ou, ainda, não teriam a possibilidade de aguardar pelo transplante renal. Da mesma forma, os trabalhadores manifestaram a satisfação 
em constatar que, ao final das quatro horas de hemodiálise, o paciente encontrava-se visivelmente melhor em relação a quando chegou ao serviço, especialmente, sem "o excesso de líquido", como se pode identificar nos fragmentos abaixo.

Tu consegue fazer as coisas, ver o resultado do que tu faz (TE 5).

Tu vê resultado, porque tu vê um paciente dialisar 20 anos, como eu já vi. De certa forma te orgulha, tu poder manter ele por mais tempo, por muito tempo, isso faz com que tu veja que teu trabalho é bom (TE 2).

Nas últimas décadas, o desenvolvimento da tecnologia em diálise permitiu um prolongamento de sobrevida do paciente renal crônico, já que, há pouco tempo, a média de tempo de vida do paciente em diálise era de cinco anos. Atualmente, é possível encontrar pacientes que estão em diálise há 20 anos, ${ }^{10}$ o que remete à descrição da dinâmica do trabalho no serviço de hemodiálise estudado.

O trabalho permite ao indivíduo o desenvolvimento de suas potencialidades por meio da liberdade de expressão e utilização da criatividade, o que remete à satisfação e conscientização de seu papel para a organização em que atua e para a sociedade em que está inserido. ${ }^{11}$

Assim, constatar que a sua atuação contribui para manter a vida dos pacientes é uma importante característica da dinâmica do trabalho em serviços de hemodiálise, o que pode repercutir positivamente no sentido atribuído ao trabalho e, consequentemente, na autoestima, satisfação e identidade profissional dos trabalhadores de enfermagem inseridos nesse contexto laboral.

Na categoria complexidade do trabalho mediada pela técnica e interação, os profissionais discorreram acerca da complexidade técnica do procedimento hemodialítico e das relações afetivas, uma vez que interagem sempre com os mesmos pacientes, em situação de fragilidade física e emocional.

No que tange à complexidade técnica do procedimento hemodialítico, houve uma unanimidade ao afirmarem que é um trabalho que exige conhecimento específico, habilidade técnica, vigilância constante e intervenção imediata nas intercorrências. Esses aspectos podem ser observados nos fragmentos a seguir:

[...] o trabalho em hemodiálise é bem complexo [...] exige muito da pessoa (AE 4).

[...] é um trabalho que exige bastante, com muita complexidade. A hemodiálise não é simples [...] pode ter várias intercorrências (E 2).
No que se refere à complexidade das relações afetivas entre os trabalhadores de enfermagem e os pacientes em hemodiálise, observa-se que atuar sempre junto dos mesmos pacientes é uma importante característica em hemodiálise, pois os pacientes frequentam o serviço geralmente três vezes por semana, em turnos pré-determinados e durante anos.

Conforme os trabalhadores, a convivência possibilita o estabelecimento de vínculo entre os pacientes e os membros da equipe de enfermagem que, muitas vezes, conhecem a história de vida de alguns pacientes, nutrindo carinho, apego e envolvimento com os mesmos.

Entretanto, essa relação de proximidade desperta sentimentos ambíguos: por um lado existe a gratificação diante do reconhecimento e carinho dos pacientes; por outro, há o desgaste frente às demandas advindas da convivência e das necessidades, especialmente afetivas, desses pacientes. Esse aspecto pode ser observado no fragmento que segue:

[...] é um trabalho gratificante, mas desgastante, porque a gente passa a ser, talvez, a família que eles não têm (E1).

Da mesma forma, essa relação de proximidade também permite que os pacientes conheçam cada membro da equipe de enfermagem, o que pode implicar em certo desconforto nos trabalhadores, uma vez que necessitam demonstrar que "estão sempre de bom humor". Isso pode ser evidenciado no fragmento abaixo:

[...] é difícil, tu tem que estar sempre de bom humor, qualquer coisa eles percebem, se tu não está bem, eles já te conhecem e comentam (AE2).

O setor de hemodiálise é muito enriquecedor no que diz respeito à interação entre os pacientes e a equipe de enfermagem, pois favorece o estabelecimento de uma relação de proximidade em que, muitas vezes, os trabalhadores possuem um amplo conhecimento sobre o paciente, seu contexto familiar e seu processo de saúde/doença. ${ }^{12}$

A nefrologia é uma área em que a natureza do trabalho não requer apenas conhecimento técnico, mas também uma grande participação emocional do trabalhador ${ }^{10}$. Assim, a situação de adoecimento crônico dos pacientes, somada à convivência por longos períodos, durante anos, com os mesmos pacientes, e a necessidade de conhecimento técnico-científico específico dos trabalhadores para a realização do procedimento hemodialítico caracterizam a complexidade que 
permeia a dinâmica do trabalho da enfermagem no serviço de hemodiálise.

O trabalho rotineiro marcado pela pressão do tempo e repetição, terceira categoria do eixo temático da dinâmica do trabalho no serviço de hemodiálise, remete a algumas características do processo de trabalho no serviço de hemodiálise, como a sua realização em turnos, a necessidade de desenvolver as atividades em um determinado espaço de tempo, a execução do mesmo procedimento diariamente e, com isso, a repetição de tarefas, além do fato de serem os mesmos pacientes, como já foi mencionado anteriormente. Os profissionais referiram gostar da rotina e que, mesmo sendo difícil a adaptação inicial, a rotina facilita a realização do trabalho, conforme explicitado nos fragmentos abaixo:

[...] aqui é uma rotina, mas não é a mesma coisa todo o dia (TE6).

[...] no inicio é difícil, tem que se adequar às rotinas, mas a gente vai se adequando e gostando (AE4).

[...] uma coisa que estraga o meu plantão é errar uma punção, porque a ideia é acertar [...] (TE3).

[...] procuro fazer a coisa mais correta possível, nada que prejudique a hemodiálise do paciente. É o cuidado com o material para não infectar, não contaminar, hemodiálise sem risco maior, observar os pacientes, cuidar deles (AE1).

Além da pressão do tempo, percebe-se por meio das falas que existe a pressão por "acertar", principalmente no sentido de proporcionar o bom andamento da sessão de hemodiálise, evitando comprometer o cuidado ao paciente.

$\mathrm{O}$ estabelecimento de normas, rotinas e regulamentos é necessário para o funcionamento efetivo dos serviços de saúde, mas a rigidez das normas e rotinas pode repercutir negativamente na qualidade da assistência prestada. ${ }^{3}$

Um estudo ${ }^{13}$ evidenciou que as auxiliares de enfermagem se sentiam pressionadas pelo tempo que possuíam para a realização das atividades e pelos próprios pacientes, sentindo-se constantemente ameaçadas, pois as falhas são facilmente identificadas. O que converge com a "pressão por acertar", característica da dinâmica no serviço de hemodiálise.

A organização e dinâmica do trabalho de enfermagem em hemodiálise exigem rapidez e conhecimento na execução das tarefas cotidianas. A pressão do tempo e por realizar os procedimentos de forma correta, somadas à complexidade técnica e das relações afetivas com os pacientes caracterizam a dinâmica da enfermagem no serviço de hemodiálise. Além disso, outra particularidade, nesse contexto laboral, é a possibilidade dos profissionais atribuírem sentido ao trabalho realizado, diante da melhora clínica e manutenção da vida dos pacientes.

\section{A percepção dos trabalhadores de enfermagem sobre os pacientes em hemodiálise}

Neste eixo temático emergiram três categorias: não aceitação da doença pela dependência do tratamento, relações familiares e sociais prejudicadas pela doença e a equipe de enfermagem como referência afetiva.

Na categoria não aceitação da doença pela dependência do tratamento, os trabalhadores de enfermagem referiram que a maioria dos pacientes tem dificuldades em aceitar a condição de "dependente da máquina", apresentando-se, muitas vezes, revoltados e não aderentes ao tratamento, como se pode observar nos fragmentos que se seguem. (TE3).

[...] depender da máquina, é um problema

Eles vêem a hemodiálise como um castigo (AE3).

Para muitos deles é um sacrifício vir aqui (AE4).

O paciente em hemodiálise vive um conflito diário em que oscila do amor ao ódio em relação ao tratamento; por um lado, tem a consciência de que a hemodiálise é indispensável para a manutenção de sua vida, mas, por outro, o tratamento o faz perceber a fragilidade de sua condição de saúde. ${ }^{12}$ Esse sentimento de ambivalência em relação ao tratamento também foi apontado em uma investigação com pacientes em hemodiálise, o que converge com a percepção dos trabalhadores de enfermagem pesquisados neste estudo. ${ }^{14}$

Para o doente com insuficiência renal crônica, o tratamento hemodialítico é necessário, evidenciando que não há como ser diferente, não existe opção, ele necessita do tratamento, ficando claro que existem situações na vida que independem da vontade e fogem ao controle do indivíduo. ${ }^{15}$

A percepção dos trabalhadores de enfermagem pesquisados neste estudo, expressa por palavras como "dependência", "problema", "castigo" e "sacrifício", remete aos resultados de uma pesquisa ${ }^{16}$ realizada em unidades de hemodiálise em que os pacientes mencionaram ter a sensação de que o tempo não passa durante as 
quatro horas de tratamento, e que o fato estarem "presos" à máquina de hemodiálise é motivo de angústia, uma vez que anseiam pelo momento de tornarem-se "libertos", ou seja, o momento de término da sessão.

Os trabalhadores percebem que os pacientes não aceitam a doença, o que é traduzido por sentimentos de revolta e a não adesão ao tratamento, muitas vezes como forma de negação da condição crônica, como se observa nos fragmentos abaixo:

[...] eles [os pacientes] são de muito difícil aceitação da doença (TE1).

[...] eles [os pacientes] têm resistência, à questão dos alimentos, da água [...] (TE4).

[...] eu acho que por eles [os pacientes] se considerarem muito atingidos, eles não se sentem só doentes, eles se sentem especiais pela doença que têm (AE3).

Os pacientes portadores de IRC podem se sentir diferentes e excluídos diante das inúmeras e contínuas restrições impostas pela doença e tratamento, como, por exemplo, a rigorosa restrição alimentar e de ingesta hídrica, a necessidade de medicações de uso contínuo e a obrigatoriedade de se submeterem ao tratamento dialítico como condição inerente à manutenção de suas vidas. ${ }^{6}$

Em outra categoria, relações familiares e sociais prejudicadas pela doença, os trabalhadores percebiam que muitos pacientes tinham suas relações familiares e sociais prejudicadas pela doença e necessidade de hemodiálise. Elas relataram que alguns pacientes são abandonados pela família e que é comum o afastamento dos amigos e o isolamento social em função da doença e do tratamento. Os fragmentos a seguir ilustram a categoria.

Nós temos pacientes abandonados pela família

Quando ficam doentes, eles perdem os amigos, família [...] com a hemodiálise eles deixam de ir às festas, ao futebol, no início pela restrição hídrica e alimentar, e depois eles vão ficando cada vez mais sozinhos (TE5).

A Insuficiência Renal Crônica impõe uma série de limitações físicas, sociais e emocionais, incluindo dificuldades no desempenho ocupacional, restrições hídricas, dietas especiais, consultas médicas e sessões de hemodiálise, tornando a pessoa frágil e desestruturando seu cotidiano, que é permeado por perdas que vão além da função renal ${ }^{17}$, conforme relata TE5.

Um estudo sobre a vida cotidiana de pacientes em hemodiálise evidenciou a importância do apoio familiar para o enfrentamento das ad- versidades oriundas da doença, como fonte de motivação e encorajamento para a continuidade do tratamento. ${ }^{14}$

O paciente, na maioria das vezes, precisa compartilhar o enfrentamento das adaptações e restrições desencadeadas pela doença com a família ou com pessoas próximas, a fim de obter ajuda e apoio, uma vez que a doença e o tratamento requerem adaptação individual e familiar. Porém, nem sempre as famílias conseguem prover o apoio necessário nessas situações. ${ }^{6}$

No que se refere ao isolamento social, um estudo $^{18}$ aponta que a condição crônica implica um grande número de restrições de vida que, somadas à elevada carga emocional que o paciente precisa suportar, favorece o isolamento social, pois os pacientes tendem a evitar situações embaraçosas em que precisem explicar sobre sua doença ou condição.

Na categoria a equipe de enfermagem como referência afetiva, os trabalhadores afirmaram que a equipe de enfermagem, em algumas situações, torna-se a referência afetiva para os pacientes em hemodiálise, tendo em vista os laços de amizade construídos durante o convívio e os momentos de escuta durante as sessões de hemodiálise, o que pode ser observado nos fragmentos que se seguem.

A gente passa a ser a família deles, porque eles perdem muito as referências e vêm buscar essas referências na gente (E2).

A gente adquire uma amizade, vira uma família [...] eles se tornam nossos amigos (AE3).

Os pacientes em hemodiálise formam vínculos afetivos intensos com a equipe de saúde, e o apoio da equipe é fundamental para aceitação e adaptação do paciente à doença e ao tratamento. ${ }^{14}$ Acredita-se que a constituição desses vínculos afetivos com os pacientes também repercute na atribuição de sentido ao trabalho realizado e, consequentemente, na satisfação profissional dos trabalhadores que prestam cuidados.

Destaca-se a interação que se estabelece entre o paciente renal crônico e a equipe de saúde, já que, em muitos momentos do tratamento, essa condição fomenta uma inevitável relação de dependência por parte do paciente para com os profissionais. ${ }^{15}$ Essa interação e relação de dependência podem ser observadas na fala de E2, quando menciona a busca "de referências" na equipe de enfermagem.

Um estudo realizado com idosos em tra- 
tamento hemodialítico ${ }^{18}$ evidenciou que a enfermagem não tem como se abster da interação com esses pacientes, e que a falta da devida atenção familiar e profissional pode repercutir negativamente no cuidado de si, o que é preocupante, ao se considerar as situações de abandono familiar e isolamento social de alguns pacientes, relatadas pelos trabalhadores.

Os resultados deste estudo reforçam os achados do estudo supracitado ${ }^{18}$, uma vez que os trabalhadores de enfermagem demonstraram conhecer os sentimentos dos pacientes em relação à doença, ao tratamento, à família e à equipe de enfermagem que, muitas vezes, passa a ser a "família" desses pacientes.

\section{CONSIDERAÇÕES FINAIS}

Pode-se afirmar que o trabalho de enfermagem na hemodiálise é dinâmico, complexo e rotineiro e, além disso, permite ao trabalhador perceber a materialização do resultado da sua atuação diariamente, por meio da melhora clínica e manutenção da vida do paciente, o que se constitui em um diferencial nesse contexto laboral, em relação às outras áreas de atividade da enfermagem.

Este estudo possibilitou conhecer a percepção dos trabalhadores de enfermagem acerca do paciente em tratamento hemodialítico. Eles referiram que os pacientes em hemodiálise possuem dificuldade de aceitação da doença em função da dependência do tratamento, e também que eles perdem as referências familiares e sociais, e buscam essas referências na equipe de enfermagem.

Evidencia-se a complexidade que permeia o trabalho da enfermagem no serviço de hemodiálise, no que se refere ao estabelecimento de relações afetivas entre os membros da equipe e os pacientes em hemodiálise, uma vez que a perda das referências sociais e familiares dos pacientes somada à vivência cotidiana, durante anos de tratamento, por um lado, favorece o estabelecimento laços de amizade, mas, por outro, desgasta os trabalhadores diante das demandas afetivas de alguns pacientes.

Ao conhecer a percepção dos trabalhadores em relação aos pacientes em tratamento hemodialítico e a dinâmica do trabalho da enfermagem em serviços de hemodiálise, emergiram novas inquietações sobre as temáticas, como o prazer/ sofrimento no trabalho da enfermagem em serviços de hemodiálise e a saúde do trabalhador, ainda pouco exploradas em estudos brasileiros.
Como possível limitação do estudo, menciona-se o fato de ter sido realizado em um único serviço de hemodiálise do interior do Rio Grande do Sul, o que remete à necessidade de investigações futuras em serviços de hemodiálise de outras regiões do país, a fim de se comparar os resultados e, assim, apontar divergências e consonâncias em diferentes realidades.

\section{REFERENNCIAS}

1. Beck CLC, Prestes FC, Tavares JP, Silva RM, Prochonow AG, Nonnenmacher CQ. Identidade profissional de enfermeiros de serviços de saúde municipal. Cogitare Enferm. 2009 Mar-Mai; 14(1):114-9.

2. Trindade LL, Kirchhof ALC, Beck CLC, Grando MG. Work of ambulatorial nursing: a descriptive study on the implications in the health of the worker. Online Braz J. Nurs. 2006 [acesso 2009 Abr 30]; 5(2). Disponível em: http://www.uff.br/objnursing/ index.php/nursing/article/view/390/91

3. Beck CLC, Denardin ML, Gonzales RB. A banalização das crises vivenciadas pelas enfermeiras no mundo do hospital. Rev Técnico Cient Enferm. 2005 OutDez; 3(13):479- 85.

4. Barbosa DA, Belasco AGS. Desafios e estratégias para a enfermagem em nefrologia no cenário da globalização. Acta Paul Enferm. 2008; 21(Spe):vii.

5. Riella MC. Princípios de nefrologia e distúrbios hidroeletrolíticos. $4^{\mathrm{a}}$ ed. Rio de Janeiro (RJ): Guanabara Koogan; 2003.

6. Queiroz MVO, Dantas MCQ, Ramos IC, Jorge MSB. Tecnologia do cuidado ao paciente renal crônico: enfoque educativo-terapêutico a partir das necessidades dos sujeitos. Texto Contexto Enferm. 2008 Jan-Mar; 17(1):55-63.

7. Sesso R, Lopes AA, Thomé FS, Bevilacqua JL, Junior JER, Lugon J. Relatório do Censo Brasileiro de diálise, 2008. J Bras Nefrol. 2008 Out-Dez; 30(4):233-8.

8. Ministério da Saúde (BR), Conselho Nacional de Saúde, Comissão Nacional de Ética em Pesquisa. Resolução n ${ }^{\circ} 196$ de 10 de outubro de 1996: diretrizes e normas regulamentadoras de pesquisa envolvendo seres humanos. Brasília (DF): MS; 1996.

9. Minayo MCS. O desafio do conhecimento: pesquisa qualitativa em saúde. $10^{a}$ ed. São Paulo (SP): Hucitec; 2007.

10. Ibrahim SY. Psiconefrologia: a enfermagem em nefrologia como agente de transformação. In: Lima, EX; Santos I, organizador. Atualização de enfermagem em nefrologia. Rio de Janeiro (RJ): Sociedade Brasileira de Nefrologia; 2004. p.43-67.

11. Gomes GC, Filho WDL, Erdmann AL. O sofrimento psíquico dos trabalhadores de UTI interferindo no seu modo de viver a enfermagem. Rev Enferm. UERJ. 2006 Jan-Mar; 14(1):93-9. 
12. Koepe GBO, Araujo STC. A percepção do cliente em hemodiálise frente à fístula artério venosa em seu corpo. Acta Paul Enferm. 2008; 21(Spe):147-51.

13. Sznelwar L, Uchida S. Ser auxiliar de enfermagem: um olhar sobre da psicodinâmica do trabalho. Revista Produção. 2004 Set-Dez; 14(3):87-98.

14. Pereira LP, Guedes MVC. Hemodiálise: a percepção do portador renal crônico. Cogitare Enferm. 2009 Out-Dez; 14(4):689-95.

15. Pietrovski V, Dall'Agnol CM. Situações significativas no espaço-contexto da hemodiálise: o que dizem os usuários de um serviço? Rev Bras Enferm. 2006 SetOut; 59(5):630-5.
16. Brasil MLS, Schwartz E. As atividades lúdicas em unidade de hemodiálise. Acta Sci, Health Sci. 2005 Jan-Jun 27(1):9-18.

17. Bezerra KV, Santos JLF. O cotidiano de pessoas com insuficiência renal crônica em tratamento hemodialítico. Rev Latino-am Enferm. 2008 Jul-Ago 16(4): 686-691.

18. Lenardt MH, Hammerschmidt KSA, Borghi ACS, Vaccari E, Seima MD. O idoso portador de nefropatia diabética e o cuidado de si. Texto Contexto Enferm. 2008 Abr-Jun; 17(2):313-20. 